\title{
Interrelationships among follicles during the common-growth phase of a follicular wave and capacity of individual follicles for dominance in mares
}

\author{
E L Gastal, M O Gastal, M A Beg and O J Ginther \\ Eutheria Foundation, Cross Plains, Wisconsin 53528, USA \\ Correspondence should be addressed to O J Ginther, Animal Health and Biomedical Science, 1656 Linden Drive, University of \\ Wisconsin, Madison WI 53706, USA; Email: ginther@svm.vetmed.wisc.edu
}

( $E$ L and M O Gastal are on leave from the Departments of Veterinary and Animal Science respectively, Federal University of Viçosa, Viçosa, Brazil)

\begin{abstract}
The changing diameter interrelationships among follicles during the interval from emergence to deviation (common-growth phase) were studied in 59 mares. All follicles of $\geq 6.0 \mathrm{~mm}$ were ablated 10 days after ovulation. The four largest follicles of the postablation wave were ranked D1, D2, D3 and D4 at the expected beginning of deviation (D1 $\geq 20.0 \mathrm{~mm}$ ), according to descending diameter. The four follicles were also ranked independently, according to order of emergence at 6.0-6.9 mm as E1 (first to emerge), E2, E3 and E4. The follicles emerged during $1.3 \pm 0.1$ to $3.1 \pm 0.1$ days, and expected deviation began $6.5 \pm 0.1$ days after ablation. The frequency of emerging follicles becoming the largest follicle at the beginning of deviation was different $(P<0.0001$; chi-square test) among follicles E1 $(61 \%)$, E2 $(25 \%)$, E3 $(9 \%)$ and E4 $(5 \%)$. There were no differences in growth rates among the four follicles throughout the common-growth phase (overall, $2.8 \pm 0.04 \mathrm{~mm} / \mathrm{day}$ ). The differences in diameters between follicles E1 and E2 were similar between 3 days $(2.7 \pm 0.2 \mathrm{~mm})$ and 6 days $(2.9 \pm 0.4 \mathrm{~mm})$ after ablation. In controls and after ablation of D1; D1 and D2; or D1, D2 and D3 at the expected beginning of deviation, the largest remaining follicle became dominant in 26 of 34 mares (76\%). In 10 of 15 mares (67\%), the second-largest follicle became dominant when the largest follicle was ablated 1 or 2 days after the expected beginning of deviation. Results indicated the following: 1) the first follicle to emerge maintained its diameter advantage in most mares and average diameter growth rates were similar among the four follicles throughout the common-growth phase; 2 ) the hypothesis was supported that the capacity for dominance is similar among the four largest follicles at the beginning of deviation, but dominance by a smaller follicle is blocked when a larger follicle is present; and 3) the second-largest follicle retained the capacity for dominance in most mares for as long as $\mathbf{2}$ days after the beginning of deviation.
\end{abstract}

Reproduction (2004) 128 417-422

\section{Introduction}

The ovulatory wave in mares emerges midway during an interovulatory interval of 22-24 days. After emergence, the follicles of a wave develop in a common-growth phase for several days (reviewed in Ginther et al. 2001a, 2003). At the end of the common-growth phase, a distinctive change in growth rates commences, wherein the developing dominant follicle maintains its growth rate, and the remaining follicles (subordinate follicles) grow at a reduced rate and regress. This process is called deviation and begins when the two largest follicles on average are 22.5 and $19.0 \mathrm{~mm}$. The future dominant follicle emerges earlier on average than the future largest-subordinate follicle. In heifers, the diameters of the two largest follicles increase in parallel during $16 \mathrm{~h}$ before the end of the common-growth phase, and smaller follicles increase at a slower rate (Ginther et al. 2001b). In mares, follicle interrelationships during the common-growth phase have been given limited attention. Available information is based on a two-follicle model; two follicles were retained and other follicles were ablated as they developed (Gastal et al. 1997). The two follicles grew in parallel, but interchange with smaller follicles was precluded.

In heifers, many follicles of the wave have the capacity of becoming the dominant follicle. The potential of individual follicles for dominance at the expected beginning of deviation has been shown by ablating various follicles, according to rank (Ginther et al. 2001b). A hierarchical position was demonstrated, with the largest retained follicle in the most favored position for dominance. 
In addition, the second-largest follicle retains the capacity for dominance for about another day after the beginning of deviation. In mares, critical information on the potential for dominance among follicles at the beginning of deviation is not available. In the studies that have been done, the two-follicle model was used. When the largest follicle was ablated at the expected beginning of deviation, the second-largest follicle continued to grow without interruption (Gastal et al. 1999) and became dominant and ovulated in most mares. In a study (Ginther et al. 2004) in which all follicles of the postablation wave were retained, the largest follicle was ablated $24 \mathrm{~h}$ after the expected beginning of deviation, and the second-largest follicle usually did not become dominant. However, the second-largest follicle had been punctured for injection and sampling, an operation which may have altered its ability to become dominant.

The objectives of the present experiment in mares were as follows: 1) to characterize the interrelationships among follicles at emergence of each follicle and throughout the common-growth phase, 2) to test the hypothesis that the capacity for dominance is similar among the four largest follicles at the expected beginning of deviation but dominance by a smaller follicle is blocked when a larger follicle is present, and 3) to determine the capacity for dominance by the second-largest follicle during the 2 days after the beginning of deviation.

\section{Materials and Methods}

\section{Animals and ultrasonography}

Mares were handled in accordance with the Guide for Care and Use of Agricultural Animals in Agricultural Research and Teaching. A total of 59 mares was used during June-August of the ovulatory season in the Northern Hemisphere (lat $43^{\circ} \mathrm{N}$ ). The mares were mixed breeds of ponies, 8-17 years of age, and weighed $300-400 \mathrm{~kg}$. The feeding program and the equipment and techniques for transrectal and transvaginal ultrasound scanning, manipulation of ovaries and tracking of follicles have been described (Gastal et al. 1997). Ultrasound scanning of follicles was done every day to detect ovulations. A new follicular wave was induced by ablation of all follicles of $\geq 6 \mathrm{~mm} 10$ days after ovulation, as described; no difference was found in deviation or follicle growth between controls and follicle-ablated mares. The ablations were done to eliminate follicles from previous waves to facilitate tracking individual follicles of the postablation wave. After ablation, follicles were tracked and measured every day, using the mean width and length at the apparent maximal trans-sectional area.

\section{Common-growth phase}

The common-growth phase of a follicular wave was defined as beginning at emergence of follicles at 6.0$6.9 \mathrm{~mm}$ and extending until and including the beginning of expected deviation (largest follicle of $\geq 20.0 \mathrm{~mm}$ ). The four largest follicles at the end of the common-growth phase or at the expected beginning of deviation were ranked D1, D2, D3 and D4 (D = deviation), according to descending diameter. The same four follicles were ranked at emergence as E1, E2, E3 and E4 (E= emergence), according to order of emergence (earliest to latest). When two or more follicles emerged on the same day, they were ranked according to diameter (largest to smallest). Ties (two follicles having the same diameter) were resolved by using diameters on subsequent days. The growth of follicles during the common-growth phase was studied beginning on the day of emergence for each follicle. Follicles that did not grow beyond $6.0 \mathrm{~mm}$ were not considered. When a follicle did not have a recorded diameter of $6.0-6.9 \mathrm{~mm}$, the diameter nearest to 6.0 or $6.9 \mathrm{~mm}$ was used to represent the day of emergence. The day of ablation of all follicles of $\geq 6 \mathrm{~mm} 10$ days after ovulation was the reference point for emergence. Comparisons of the diameter of the four follicles began 3 days after ablation (first day with data for all four follicles). Comparisons were discontinued 6 days after ablation to minimize overlapping with the days after the beginning of deviation (mean interval from ablation to deviation, $6.5 \pm 0.1$ days). The growth rate per day for each follicle was determined 3-6 days after ablation, and growth rates were compared among the four follicles. For illustrative purposes, the average day of emergence for each follicle was used to place the follicles on the postablation day scale.

Follicles were compared among the four ranks (E1, E2, E3 and E4) for growth rates, day of the end of the commongrowth phase (same as beginning of deviation), frequency for maintenance of ranking for each follicle from emergence to the end of the common-growth phase, and length of interval from ablation to end of the common-growth phase. In addition, the total number of follicles emerging during the common-growth phase and their distribution throughout the phase were characterized.

\section{Interval from deviation to ovulation}

The end of the growth phase or the expected beginning of deviation (day 0) was defined by the day the largest follicle (D1) first reached $\geq 20 \mathrm{~mm}$ (Gastal et al. 1999). This was done to obtain actual diameters with an average of approximately $22.5 \mathrm{~mm}$. Forty-nine of the 59 mares used in the study of the common-growth phase were used to study the capacity for dominance. The mares were assigned to six groups: control (no ablations); ablation of D1 on day 0 ; ablation of D1 and D2 on day 0 ; ablation of D1, D2 and D3 on day 0; ablation of D1 on day 1; and ablation of D1 on day 2. The effect of ablation of various follicles on the development of dominance by the retained follicles was compared among groups. Ablation of designated follicles on days $0-2$ was done by transvaginal-ultrasound guided aspiration of follicle contents, as previously described (Gastal et al. 1999). 
Characterization end points after the end of the common-growth phase were length of interval to ovulation, number of follicles emerging during the deviation-to-ovulation interval, maximum diameter reached by the follicles and maximum diameter of the preovulatory follicle. Differences among the six experimental groups were examined for these end points.

\section{Statistical analyses}

End points with sequential data were analyzed to determine the effects of group, day and an interaction, using SAS mixed procedure with a repeated statement to account for the autocorrelation between sequential measurements (Version 8.2; SAS Institute, Cary, NC, USA) and mare within group as the random effect. If a significant $(P<0.05)$ effect of group or a group-by-day interaction was detected, paired $t$-tests were used to locate the mean differences between groups within a day. One-way analyses were done with ANOVA. The differences in outcome of follicles among groups were analyzed by chi-square test. A probability of $P \leq 0.05$ indicated that a difference was significant, and probabilities between $P>0.05$ and $P \leq 0.1$ indicated that a difference approached significance.

\section{Results}

For follicles E1, E2, E3 and E4 (largest to smallest), the percentage emerging on each day (Fig. 1), days of emergence, and diameters over $1-6$ days after ablation (Fig. 2) are shown. After ablation of all follicles of $\geq 6 \mathrm{~mm} 10$ days after ovulation, the mean days of emergence at 6.0$6.9 \mathrm{~mm}$ for follicles E1, E2, E3 and E4 were $1.3 \pm 0.1$, $1.9 \pm 0.1,2.6 \pm 0.2$ and $3.1 \pm 0.1$ days respectively. The interval between emergence of follicles E3 and E4 $(0.4 \pm 0.1$ days $)$ was shorter $(P<0.05)$ than the interval between E2 and E3 (0.7 \pm 0.1 days) and approached

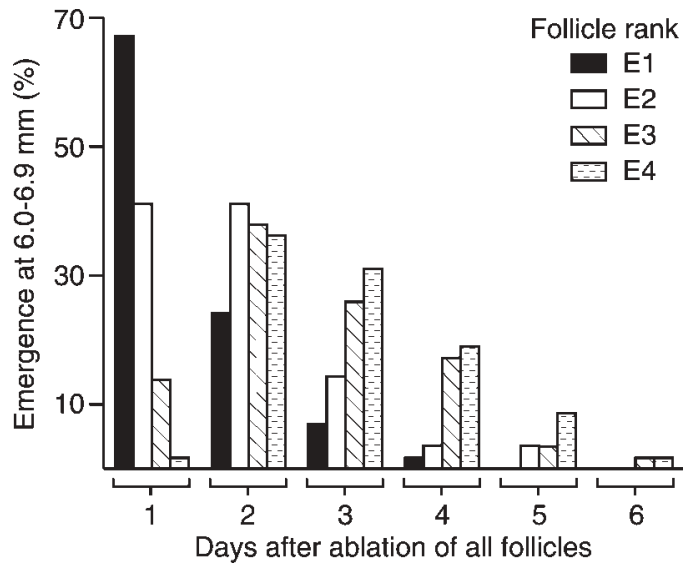

Figure 1 Mean percentage of follicles emerging for four largest follicles during $1-6$ days after ablation of all $\geq 6.0 \mathrm{~mm}(n=59$ mares). The four follicles were ranked E1, E2, E3 and E4 according to descending order on the day of emergence.

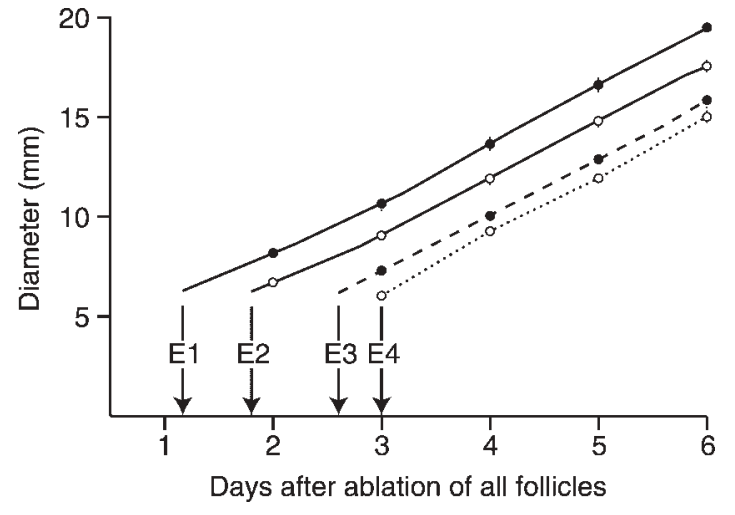

Figure 2 Mean \pm S.E.M. diameters of four largest follicles (E1, E2, E3 and E4) during $1-6$ days after ablation of all follicles $\geq 6.0 \mathrm{~mm}$ ( $n=59$ mares). The four follicles were ranked according to descending order on the day of emergence. $\mathrm{E}=$ mean day of emergence for each follicle.

being shorter $(P<0.1)$ than the interval between $\mathrm{E} 1$ and E2 $(0.6 \pm 0.1$ days). The frequency of identical ranking of a follicle at both emergence and the beginning of deviation was different $(P<0.0003)$ among follicles $(E 1=D 1$, 36/59 mares, 61\%; E2 = D2, 20/59, 34\%; E3 = D3, $14 / 59,24 \%$; $E 4=D 4,22 / 59,37 \%)$. The frequency of a follicle of a given ranking at emergence becoming the largest follicle at the beginning of deviation (D1) was different $(P<0.0001)$ among follicles E1 (36/59, 61\%), E2 $(15 / 59,25 \%)$, E3 (5/59, 9\%) and E4 (3/59, 5\%). The number of all follicles, including E1, E2, E3 and E4, that emerged between 1 and 6 days after ablation (mean interval to expected deviation, $6.5 \pm 0.1$ days) was different $(P<0.001)$ among days (Fig. 3). The total number of follicles per mare emerging between the day of ablation at 10 days after ovulation and the day of expected deviation was $12.4 \pm 0.6$. During 3-6 days after ablation, there was no significant difference in growth rate among follicles E1, E2, E3 and E4 (overall, $2.8 \pm 0.4 \mathrm{~mm} /$ day). The difference in diameter between the follicles E1 and E2 at 3 days $(2.7 \pm 0.2 \mathrm{~mm}$ ) was similar (no significant difference) to the difference at 6 days $(2.9 \pm 0.4 \mathrm{~mm})$.

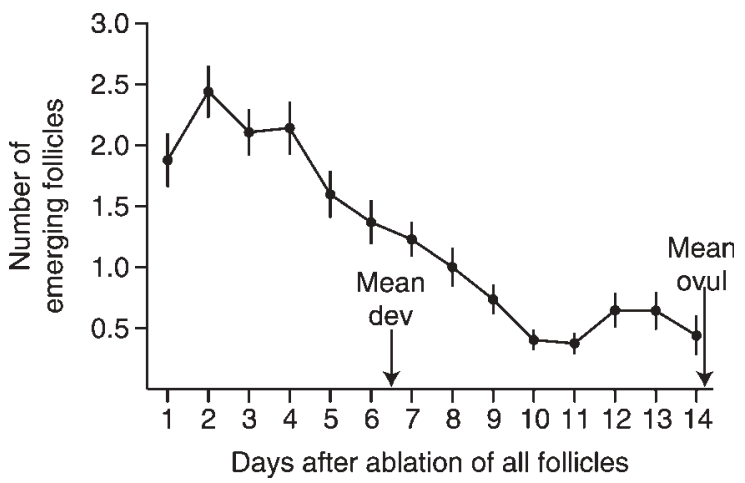

Figure 3 Mean \pm S.E.M. number of follicles emerging on each day between ablation of all follicles $\geq 6.0 \mathrm{~mm}$ and ovulation $(n=59$ mares). Mean dev = day of the expected beginning of deviation (largest follicle $\geq 20 \mathrm{~mm}$ ); mean ovul = day of ovulation. 
The diameters of D1, D2, D3 and D4 before the expected beginning of deviation (day 0) are shown (Fig. 4). The growth rates among follicles over days -3 to 0 were different $(P<0.0001)$ among follicles. The constant separation of the follicles as depicted in the means was not a feature in some individual mares. When individuals were examined, the separation between follicles D1 and D2 was continuous on days -4 to 0 in 40 of 59 mares $(67 \%)$ as illustrated by mares 1 and 2 (Fig. 4). In the remaining mares, D1 was larger for at least the last 2 days before deviation (17\%; mare 3 ) or only for the last day (day 0; $17 \%$; mare 4). During the interval from expected deviation to ovulation, there were no differences among the six experimental groups for length of the interval (overall, $7.7 \pm 0.2$ days), maximum diameter of the preovulatory follicle $(38.8 \pm 0.6 \mathrm{~mm})$, number of emerging follicles $(4.5 \pm 0.4)$ or maximum diameter of the largest follicle emerging during the interval $(12.1 \pm 0.4 \mathrm{~mm})$. The effect of follicle rank (D1, D2, D3 and D4) at the expected beginning of deviation on the frequency of dominance is shown (Table 1). There was no significant difference

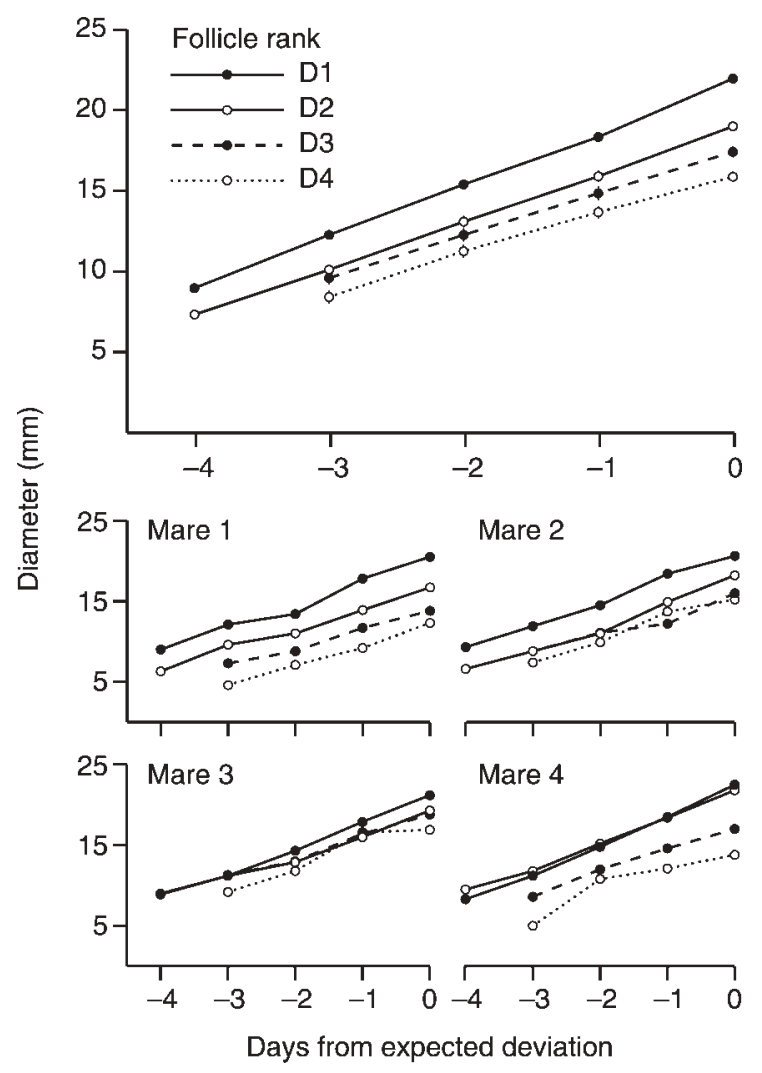

Figure 4 Mean \pm S.E.M. diameters of four follicles normalized to the beginning of expected deviation (day 0; D1 $\geq 20 \mathrm{~mm} ; n=59$ mares) and diameters for four individual mares. The four follicles were ranked D1, D2, D3 and D4 according to descending diameter on day 0 . The constant separation between D1 and D2 shown for the means occurred in $66 \%$ of individual mares, as shown for mares 1 and 2 . In the remaining mares, D1 was larger for at least day -1 and $-2(17 \%$; mare 3$)$ or only for day $0(17 \%$; mare 4$)$. among the six groups in the frequency of the largest follicle or the highest-ranking remaining follicle becoming dominant ( $\geq 30 \mathrm{~mm}$; overall frequency, 36/49, 73\%).

\section{Discussion}

Accuracy of follicle tracking was favored by the following: 1) large ovaries of mares with follicles that are about 2.6 times larger in mares than in heifers throughout a follicular wave; 2) ablation of follicles of $\geq 6.0 \mathrm{~mm}$ to initiate a new wave, providing a clear image of new follicles as they emerged; 3) an operator with 10 years' $^{\prime}$ experience on detailed follicle tracking in mares; and 4) an operator who functioned without knowledge of the expected outcome.

Previous studies of follicle emergence in mares focused on the two largest follicles or used a ranking system that was established late in the wave, such as at maximum diameter or expected or observed deviation. In the present study, the four largest follicles were ranked at the expected beginning of deviation, and the same four follicles were also ranked independently at emergence. The four largest follicles at deviation were chosen because they retrospectively encompassed the four largest follicles at emergence in the majority (53\%) of the waves; $90 \%$ of the four follicles at deviation involved three or four of the same follicles at emergence. Follicles were studied from emergence to the expected beginning of deviation or throughout the common-growth phase, beginning at emergence of each follicle.

Follicle emergence was well dispersed over days with mean intervals of 0.4-0.7 days between consecutive emergence of follicles E1, E2, E3 and E4. This was also shown by the differences among the four follicles in the percentage of each ranked follicle emerging during 1-6 days after ablation. The interval of 1.3 days from the ablation 10 days after ovulation to emergence at $6.0-6.9 \mathrm{~mm}$ of the first or largest follicle (E1) and the interval of about 0.5 days between emergence of follicles E1 and E2 were about half as long as the intervals for the two-follicle model (Gastal et al. 1997). The longer reported intervals for the two-follicle model are attributable to the elimination of all but the two follicles. In the present study, the interval between emergence of follicles was 38-64\% shorter for the two smallest follicles (E3 and E4) than for the intervals between the two larger follicles. Moreover, follicle E1 was more likely to maintain its ranking until deviation $(61 \%)$ than the other follicles $(24-37 \%)$. The average diameter growth rates after emergence of the four follicles were similar from 3 days after ablation until the mean day of the end of the growth phase 6.5 days after ablation. This was indicated by the absence of a day-byfollicle interaction and no differences between emergence and deviation in the differences in diameters among follicles. These results are consistent with the results of the two-follicle model (Gastal et al. 1997). The first follicle to emerge became the largest follicle at the beginning 
Table 1 Number of mares in which the highest ranking follicle became dominant after ablation of various follicles on various days relative to the expected beginning of deviation (day 0 ).

\begin{tabular}{|c|c|c|c|c|c|c|}
\hline \multirow[b]{3}{*}{ Highest-ranking follicle that became dominant* } & \multicolumn{6}{|c|}{ Experimental groups } \\
\hline & \multicolumn{4}{|c|}{ Follicles ablated on day 0} & \multicolumn{2}{|c|}{ D1 ablated on } \\
\hline & None & D1 & D1, D2 & D1, D2, D3 & Day 1 & Day 2 \\
\hline Largest (D1) & 7 & - & - & - & - & - \\
\hline Second largest (D2) & 1 & 6 & - & - & 5 & 5 \\
\hline Third largest (D3) & 0 & 1 & 8 & - & 2 & 0 \\
\hline Fourth largest (D4) & 0 & 0 & 0 & 5 & 0 & 0 \\
\hline Smaller than D4 & 2 & 1 & 0 & 3 & 1 & 1 \\
\hline Nonet & 0 & 0 & 0 & 0 & 0 & 1 \\
\hline
\end{tabular}

* Follicles were ranked from largest (D1) to smallest according to hierarchical position at the beginning of deviation (D1 of $\geq 20 \mathrm{~mm}$ ). Dominant follicle was defined as one that reached $\geq 30 \mathrm{~mm}$.

tA dominant follicle did not develop during the experimental wave.

of expected deviation in more mares $(61 \%)$ than for the other three follicles (5-25\%). These findings indicate that the future dominant follicle had an advantage by the time emergence occurred. In the two-follicle model, the first follicle to emerge became dominant in the majority of mares (Gastal et al. 1997), but other potential follicles for dominance were removed in preparing the model. In cattle, the future dominant follicle began as a 3 or $4 \mathrm{~mm}$ follicle about $6 \mathrm{~h}$ earlier than the future largest-subordinate follicle (reviewed in Ginther et al. 2001b, 2003). Earlier emergence of the future dominant follicle must be considered a component of the follicle selection mechanism in these farm species. In recent studies in women, a similar early advantage for the follicle that became dominant was not found (Baerwald et al. 2003a,b).

A mean of 12.0 follicles per mare, including E1, E2, E3 and E4, emerged by the end of the common-growth phase. A mean of 4.5 additional follicles emerged sporadically during the interval between the end of the commongrowth phase and ovulation. Follicles emerging near the end of the common-growth phase and during the interval between deviation and ovulation reached a small maximum diameter (mean, $12.0 \pm 0.4 \mathrm{~mm}$ ). The wave-stimulating FSH surge declines to minimal or baseline concentrations a few days after the beginning of deviation (Ginther et al. 2001a). The continued sporadic emergence of small follicles may have been a response to the low FSH concentrations. Alternatively, the follicles may emerge and grow to maximum diameters of about $12 \mathrm{~mm}$ without FSH stimulation. In cattle, follicles apparently grow to 3 or $4 \mathrm{~mm}$ without FSH stimulation (Lussier et al. 1994, Hendriksen et al. 2003).

The mean diameters of D1 $(22.0 \mathrm{~mm})$ and D2 $(19.0 \mathrm{~mm})$ at the expected beginning of deviation are close to reported diameters at observed deviation (Ginther et al. 2003). In a previous report (Ginther et al. 2001a), the follicle of a two-follicle model that first reached $\geq 17.5 \mathrm{~mm}$ and $\geq 20.0 \mathrm{~mm}$ (expected beginning of deviation) became the dominant follicle in $81 \%$ and $93 \%$ of 29 mares respectively. In the present study, the complex variability in follicle outcome from event to event was shown by the ten control mares: first follicle to emerge became the largest at deviation $(50 \% ; 61 \%$ for all 59 mares), largest follicle at deviation became the dominant follicle $(70 \%)$, and dominant follicle became the ovulatory follicle $(90 \%)$. Thus, the probability that the highest-ranking follicle would maintain its position from emergence to ovulation was $32 \%(50 \% \times 70 \%, \times 90 \%)$. In the mare in which the dominant follicle did not ovulate, the ovulatory follicle originated from a subsequent wave that began on the last day of the common-growth phase of the postablation wave. Thus, in this mare, the first postablation wave was a major anovulatory wave, as previously defined (Ginther 1993), in which the follicles intermingled with the follicles of the subsequent ovulatory wave.

The largest or highest-ranking follicle at the expected beginning of deviation in the controls or the highest-ranking remaining follicle after ablation of D1, D1 and D2, or D1, D2 and D3 on day 0 became a dominant follicle $(\geq 30 \mathrm{~mm})$ in 26 of 34 mares $(76 \%)$ totaled over the four groups, with no significant difference among groups. The absence of a significant difference among the controls and the groups with ablations on day 0 demonstrated that D2, D3 and D4 had a capacity for dominance similar to that of D1. Although each of the four follicles had a similar capacity for dominance, the actual development of dominance was usually blocked when a higher-ranking follicle was present, thereby supporting the hypothesis. In a few mares, follicles as small as D5 and D7 became dominant, demonstrating that the capacity for dominance is widespread among the follicles of the wave. Similar results have been reported for heifers (Ginther et al. 2001b).

A propensity for dominance also was shown by the largest remaining follicle (D2) when D1 was ablated 1 or 2 days after the beginning of deviation; D2 became dominant in 10/15 mares (67\%). In heifers, regression of the second-largest follicle was delayed significantly when the largest follicle was ablated at a mean diameter approximately equivalent to 1 day after the beginning of deviation, but not when the largest follicle was ablated at an 
equivalent of 2 days after deviation (reviewed in Ginther et al. 2001a). Although these results in heifers cannot be compared directly to the present results in mares, it appears that the second-largest follicle in mares retains a capacity for dominance in most mares for at least a day longer than in most heifers. In this regard, the wave-stimulating FSH surge reaches minimal concentrations within a day after deviation in heifers and a few days after deviation in mares (reviewed in Ginther et al. 2001a, 2003). It is not known whether the longer interval from deviation to the postdeviation nadir in FSH contributes to the apparent species difference in the duration of viability of the largest subordinate follicle.

In summary, follicles of $\geq 6.0 \mathrm{~mm}$ were ablated 10 days after ovulation in 59 mares. The four largest follicles of the new wave were ranked according to diameter at the expected beginning of deviation, and the four follicles were also ranked independently at emergence according to day of emergence at $6.0-6.9 \mathrm{~mm}$. The first follicle emerged an average of 1.3 days after ablation followed by an approximately half-day mean interval between emergence of subsequent follicles. The follicles grew in parallel on average until the end of the common-growth phase. The difference in diameter between the two largest follicles was similar at the beginning and end of the growth phase. When none, one, two or three largest follicles were ablated at the expected beginning of deviation, the largest remaining follicle became dominant in 26 of 34 mares $(76 \%)$, with no difference among groups. In ten of 15 mares $(67 \%)$, the second-largest follicle became dominant when the largest follicle was ablated 1 or 2 days after the beginning of deviation. The results supported the hypothesis that the capacity for dominance at the expected beginning of deviation is shared by many follicles of the wave, and the potential is greatest for the largest (highest-ranking) follicle and decreases progressively according to decreasing rank. Furthermore, the second-largest follicle retained its dominance capability in most mares for at least 2 days after the expected beginning of deviation.

\section{Acknowledgements}

This study was supported by the Eutheria Foundation and Equiservices Publishing, Cross Plains, Wisconsin, USA, Project P2-OG-03. The authors thank S. Jensen for technical assistance.

\section{References}

Baerwald AR, Adams GP \& Pierson RA 2003a A new model for ovarian follicular development during the human menstrual cycle. Fertility and Sterility 80 116-122.

Baerwald AR, Adams GP \& Pierson RA 2003b Characterization of ovarian follicular wave dynamics in women. Biology of Reproduction 69 1023-1031.

Gastal EL, Gastal MO, Bergfelt DR \& Ginther OJ 1997 Role of diameter differences among follicles in selection of a future dominant follicle in mares. Biology of Reproduction 57 1320-1327.

Gastal EL, Gastal MO \& Ginther OJ 1999 Experimental assumption of dominance by a smaller follicle and associated hormonal changes in mares. Biology of Reproduction 61 724-730.

Ginther OJ 1993 Major and minor follicular waves during the equine estrous cycle. Journal of Equine Veterinary Science 13 18-25.

Ginther OJ, Beg MA, Bergfelt DR, Donadeu FX \& Kot K 2001a Follicle selection in monovular species. Biology of Reproduction $\mathbf{6 5}$ 638-647.

Ginther OJ, Bergfelt DR, Beg MA \& Kot K $2001 b$ Follicle selection in cattle: relationship among growth rate, diameter ranking, and capacity for dominance. Biology of Reproduction 65 345-350.

Ginther OJ, Beg MA, Donadeu FX \& Bergfelt DR 2003 Mechanism of follicle deviation in monovular farm species. Animal Reproduction Science 78 239-257.

Ginther OJ, Bergfelt DR, Beg MA, Meira C \& Kot K 2004 In vivo effects of an intrafollicular injection of insulin-like growth factor 1 on the mechanism of follicle deviation in heifers and mares. Biology of Reproduction 70 99-105.

Hendriksen PJM, Gadella BM, Vos PLAM, Mullaart E, Kruip TAM \& Dieleman SJ 2003 Follicular dynamics around the recruitment of the first follicular wave in the cow. Biology of Reproduction 69 2036-2044.

Lussier JG, Matton P, Guilbault LA, Grasso F, Mapletoft RJ \& Carruthers TD 1994 Ovarian follicular development and endocrine responses in follicular-fluid-treated and hemi-ovariectomized heifers. Journal of Reproduction and Fertility 102 95-105.

Received 31 March 2004

First decision 14 May 2004

Accepted 12 July 2004 